\title{
Evaluation of sperm motility and velocity of different genetic groups of bucks using Computer-Assisted Sperm Analyzer
}

\author{
MR Islam ${ }^{1}$, MKU Talukder ${ }^{2}$, MS Rahman² and SS Husain ${ }^{1} *$
}

${ }^{1}$ Department of Animal Breeding and Genetics, Bangladesh Agricultural University, Mymensingh, Bangladesh; ${ }^{2}$ American Dairy Limited, Gazipur, Dhaka, Bangladesh

\begin{abstract}
Semen quality assessment is a prime prerequisite for any breeding programme. Computer-Assisted Sperm Analyzer (CASA) can measure the semen quality very accurately and sharply. The research was conducted at American Dairy Limited (ADL) at Vangnahati, Sreepur, Gazipur. A total of 120 ejaculates were collected from three genetic groups of bucks namely Black Bengal (BB), Boer and Jamunapari (JP) with a view to characterize and compare the semen motility and velocity parameters using ComputerAssisted Sperm Analyser. Significantly $(p<0.05)$ higher ejaculate volume was found in Boer buck $(1.73 \pm 0.16 \mathrm{ml})$ with the lower in BB buck $(0.98 \pm 0.14)$, respectively. But significantly $(p<0.05)$ higher

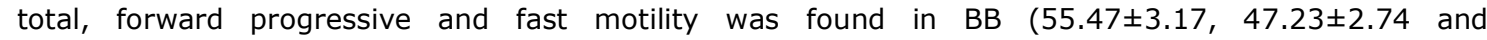
$37.62 \pm 2.40 \%)$ and lower in JP $(40.67 \pm 3.37,30.97 \pm 2.91$ and $21.81 \pm 2.55 \%)$, respectively. Significantly $(p<0.01)$ fastest straight line and average path distance was observed in Boer bucks $(12.29 \pm 1.63$ and $15.89 \pm 1.95 \mu \mathrm{m})$ than Black Bengal and Jamunapari bucks (4.38 \pm 1.19 and $7.26 \pm 1.57$; and 3.14 \pm 1.27 and $8.42 \pm 1.95 \mu \mathrm{m})$, respectively. The distance curved line (DCL) and distance straight line (DSL) was significantly $(p<0.05)$ higher in Boer $(29.13 \pm 4.87,12.29 \pm 1.63$ and $15.89 \pm 1.95 \mu \mathrm{m} / \mathrm{sec})$ and lower in BB $(22.07 \pm 4.36$ and $7.26 \pm 1.57 \mu \mathrm{m} / \mathrm{sec})$, respectively. In case of curvilinear velocity, straight line velocity and average path velocity value was significantly $(p<0.01)$ higher in Boer $(127.08 \pm 13.88$, $50.01 \pm 7.68$ and $68.13 \pm 7.25 \mu \mathrm{m} / \mathrm{sec})$ with lower in JP $(62.01 \pm 12.77,15.75 \pm 7.35$ and 22.39 \pm 9.42$)$ where as linearity and straightness was higher in Boer and lower in BB $(p>0.05)$, respectively. The scrotal circumference had positive correlations with semen volume and curvilinear velocity for all the genotypes. It was concluded that semen of Boer bucks found consistently better than other two genetic groups of bucks. Further, competitive studies with large sample may be performed to evaluate the breed specific differences in available goat breeds. I think this study also disclosed the some rare parameters of semen quality by using Computer-Assisted Sperm Analyzer which was impossible in manually. These results of the present study could be an authentic guideline in future performance tests of different genetic groups of bucks.
\end{abstract}

Key words: buck semen, motility, velocity, CASA, genetic group

\section{Introduction}

In present scenario of population blast, food security is a major issue of concern in third world country like Bangladesh. Goat has been an integral component of animal husbandry system in Bangladesh and being a potent food source that has to be utilized to its maximum potential. The production of superior progeny will further intensify commercialized goat farming that will supplement food supply (Leboeuf et al., 2000) and meet the required amount of meat $120 \mathrm{~g}$ and milk $250 \mathrm{ml}$ per head per day in Bangladesh (MoFL, 2013). The genetic up gradation solely depends upon effective breeding policy required to develop and conserve superior genotype
(Jabbar et al., 2010). This can be made possible through selection and mating of superior males and females (Bhatia and Arora, 2005). Since a male can only mate limited number of females makes natural breeding a limiting factor. Also the availability and identification of genetically superior animal in a geographical area is difficult tasks that can hinder/obstruct the success breeding program.

To overcome these problems, use of assisted reproductive technology viz. artificial insemination (AI) is utilized, where semen obtained from a desired male with superior genotype is preserved and later utilized to inseminate multiple numbers of females, enhancing superior germplasm propagation 
manifolds and also effectiveness of breeding programme with better progeny (Verma et al., 2012). Use of insemination to upgrade and improve goats breed has an upper hand over rest of the techniques (Kifaro et al., 2007). Monitored insemination not only guarantees use of superior germplasm but helpful in regulating planned breeding. Prerequisite before utilizing semen for insemination or preservation is to evaluate quality in terms of ejaculate volume, concentration, viability, motility, and velocity. Motility is one of the important seminal attribute that determines timely transport of spermatozoa to site of fertilization and has high correlation with successful conception (Anand et al., 2016). Earlier, motility was evaluated in terms of mass motility and progressive motility through visual observations. But introduction of computer assisted semen analyzer has opened up new opportunity to not only evaluate motility patterns exhibited by spermatozoa but also different path velocities associated with spermatozoa movements that are helpful in determining semen quality. However, breed specific seminal motility pattern under Bangladeshi conditions in goats have not been documented.

So, attempt was undertaken to evaluate semen quality in term of motility and path velocities in diluted semen for better evaluation, experiment was conducted to evaluate the motion characteristics and path velocities exhibited by spermatozoa in diluted semen of Black Bengal, Boer and Jamunapari buck.

\section{Materials and Methods}

\section{Study area and period}

The present research was conducted at American Dairy Limited (ADL), Vangnahati, Sreepur, Gazipur with the close supervision of Department of Animal Breeding and Genetics, Bangladesh Agricultural University, Mymensingh. The financial support of this research was provided by the ADL during the period from January to May, 2017.

\section{Source and selection of breeding bucks}

A total of 20 Boer bucks were imported from Australia, 15 Jamunapari bucks from India and 10 Black Bengal bucks from Department of Livestock Services (DLS), Bangladesh in 2016. Before selection of breeding bucks, morphometric characterization of the bucks was performed. A total of fifteen bucks were selected from three genetic groups viz. five Boer, five Jamunapari and five Black Bengal bucks based on their body weight, age, libido, scrotal circumference (SC), erection, mounting, protrusion of penis and thrust. The scrotum was inspected with respect to size, shape and free from skin disease. The trial bucks in this research were kept in intensive system and management was same for all genotypes of buck. All the genotypes of buck were ranged from 15 to 24 months of age. The body weights of BB bucks were 20 to $22 \mathrm{~kg}$, for Boer bucks it was 57 to $61 \mathrm{~kg}$ and 60 to $65 \mathrm{~kg}$ for JP bucks, respectively. Scrotal circumference was measured in centimeters using measuring tape.

\section{Semen collection and dilution}

A total of 120 ejaculates were collected from three genetic groups (40 from each groups) using artificial vagina (AV) method. Immediately after collection, the samples were kept in a water bath at $370 \mathrm{C}$ and evaluated volume $(\mathrm{ml})$ was read from the graded collection vial. After the preliminary evaluations, ejaculates were subjected to the initial dilution with prewarmed $\left(37^{\circ} \mathrm{C}\right)$ Tris-egg yolk extender.

\section{Motility and velocity evaluation}

The concentration of diluted semen, motility and velocity parameters were evaluated by Computer-Assisted Sperm Analyzer with Andro Vision AXIO, latest version 6.0.1 (Minitub GmbH12500, Germany). The software was set using the manufacturer's recommendation, with a slight adjustment to allow the clear identification of spermatozoa. The software settings adjusted with the reading: temperature of analysis $37^{\circ} \mathrm{C}$; frame rate (Frames/sec) 30; duration of data capture 15 sec.; minimum motile speed (microns/sec) 28; maximum burst speed (microns/sec) 600; Distance scale factor (microns/sec) 7.50; minimum and maximum cell size (pixels) 6; sperm count per field analysis $>1000$; minimum number of fields per sample 3 . One small drop of Tris-buffer diluted semen was placed on a clean pre-warmed $\left(37^{\circ} \mathrm{C}\right)$ slide and examined under Computer Assisted Microscope with cover slip at $20 x$ zoom. Analysis was performed at least three new fields of each of slide.

The following motility parameters such as total motility (TM) (\%), forward progressive motility (FPM) (\%), fast motility (\%) and circular motility (\%); distance parameters such as Distance Curved Line $(\mathrm{DCL})(\mu \mathrm{m})$, Distance Average Path (DAP) $(\mu \mathrm{m})$, Distance Straight Line (DSL) $(\mu \mathrm{m})$, and velocity parameters such as curvilinear velocity $(\mathrm{VCL})(\mu \mathrm{m} / \mathrm{sec})$, straight line velocity (VSL) $(\mu \mathrm{m} / \mathrm{sec})$, average path velocity (VAP) $(\mu \mathrm{m} / \mathrm{sec})$, linearity (LIN) $(\%)$, straightness (STR) $(\%)$, wobble (WOB) $(\%)$, radius ( RD) $(\mu \mathrm{m} / \mathrm{sec})$, 
rotation (ROT) ( $\mu \mathrm{m} / \mathrm{sec})$ and beat/crossfrequency $(\mathrm{BCF})(\mathrm{Hz})$ were measured by CASA analyzer.

\section{Statistical analysis}

The significant levels tested by least-squares analyses of variance using the Generalized Linear Model (GLM) procedure of the Statistical Analysis System (SAS) (SAS institute Inc., 2009) computer package, version 9.1 .3 was used to find out the effects of genotypes of bucks on semen parameters. Duncan multiple range test (DMRT) was performed to separate mean values in case of significant factors.

\section{Results}

\section{Scrotal circumference of different genetic groups of buck}

A descriptive statistics of scrotal circumference and body weight of three genetic groups of bucks is shown in Table 1 . Among three different genetic groups of bucks, it was observed that left testes length of Boer bucks $(19.66 \pm 0.91 \mathrm{~cm})$ was significantly $(p<0.01)$ higher than Jamunapri and Black Bengal bucks (15.84 \pm 0.91 and $10.60 \pm 0.91$ $\mathrm{cm})$. The same sceneries were true for right testes length.The significantly $(p<0.01)$ higher scrotal circumference was found in Boer and

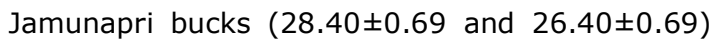
than Black Bengal bucks (21.00 \pm 0.59$)$, respectively.

\section{Ejaculate volume, concentration and motility}

The ejaculate volume and sperm motility of different genetic groups of bucks is presented in Table 2. The significantly $(p<0.05)$ highest ejaculate volume of semen was obtained in Boer bucks followed by Jamunapari bucks $(1.73 \pm 0.16$ and $1.49 \pm 0.19)$ than Black Bengal bucks $(0.98 \pm 0.14)$ (Table 2$)$. The significantly $(p<0.01)$ highest sperm count per field of diluted semen was found in Jamunapari and Boer bucks $(971.60 \pm 54.30$ and $918.14 \pm 58.33)$ while lower was in Black Bengal bucks (553.94 \pm 51.01$)$. Similarly sperm concentration per field was obtained significantly $(p<0.01)$ higher in Jamunapari and Boer bucks $\left(0.158 \pm 0.01 \times 10^{9}\right)$ and $0.149 \pm 0.01 \times 10^{9}$ ) than Black Bengal bucks $\left(0.089 \pm 0.01 \times 10^{9}\right)$. The least square mean value of total motility of diluted semen in Black Bengal and Boer bucks (55.47 \pm 3.17 and $52.27 \pm 3.62 \%$ ) were significantly $(p<0.01)$ higher than Jamunapari bucks $(40.67 \pm 3.37 \%)$. The significantly $\quad(p<0.01) \quad$ highest forward progressive motility was found in Black Bengal and Boer bucks (47.23 2.74 and $43.98 \pm 3.13 \%)$ while the lower value in Jamunapari bucks $(30.97 \pm 2.91 \%)$, respectively.

\section{Distance, velocity and progression}

Analysis of distance parameters showed that significantly $(p<0.01)$ fastest straight line and average path distance was observed in Boer bucks $(12.29 \pm 1.63$ and $15.89 \pm 1.95 \mu \mathrm{m})$ than Black Bengal and Jamunapari bucks (4.38 \pm 1.19 and $7.26 \pm 1.57$; and $3.14 \pm 1.27$ and $8.42 \pm 1.95$ $\mu \mathrm{m})$ (Table 3 ). In case of velocity parameters, the significantly $(p<0.01)$ fastest curvilinear, straight line and average path velocity sperm was observed in Boer bucks (127.08 \pm 13.88 , $50.01 \pm 7.68$ and $68.13 \pm 7.25 \mu \mathrm{m} / \mathrm{s}$ ) while lower in Black Bengal and Jamunapari bucks $(63.73 \pm 11.51, \quad 16.38 \pm 6.17$ and $24.26 \pm 5.83$; $62.01 \pm 12.77, \quad 15.75 \pm 7.35$ and $22.39 \pm 9.42$ $\mu \mathrm{m} / \mathrm{s})$.

Table 1: Morphological characteristics of three genotypes of bucks

\begin{tabular}{|c|c|c|c|c|}
\hline \multirow{2}{*}{ Factor } & \multicolumn{3}{|c|}{ Genotype } & \multirow{2}{*}{$\begin{array}{c}\text { Level of } \\
\text { Significance }\end{array}$} \\
\hline & Black Bengal & Boer & Jamunapari & \\
\hline LTL (cm) & $10.60^{c} \pm 0.91$ & $19.66^{\mathrm{a}} \pm 0.91(5)$ & $15.84^{\mathrm{b}} \pm 0.91$ & $* *$ \\
\hline $\mathrm{RTL}(\mathrm{cm})$ & $10.54^{c} \pm 0.84$ & $19.74^{\mathrm{a}} \pm 0.84$ & $15.66^{b} \pm 0.85$ & $* *$ \\
\hline $\mathrm{SC}(\mathrm{cm})$ & $21.00^{b} \pm 0.59$ & $28.40^{\mathrm{a}} \pm 0.69$ & $26.40^{\mathrm{a}} \pm 0.69$ & ** \\
\hline
\end{tabular}

$\mathrm{LTL}=$ Left Testis Length, RTL= Right Testis Length, $\mathrm{SC}=$ Scrotal Circumference, Means with different superscripts within the same row differed significantly; $* *=$ Significant at $1 \%(p<0.01)$ level of probability, Figures in the parentheses indicate the number of observation. 
Islam et al. (2019) Bang. J. Anim. Sci. 48 (2):67-74

Table 2: Least square means along with standard error for motility parameters of three genotypes of bucks

\begin{tabular}{|c|c|c|c|c|}
\hline \multirow{2}{*}{ Parameter } & \multicolumn{3}{|c|}{ Genotype } & \multirow{2}{*}{$\begin{array}{c}\text { Level of } \\
\text { Significance }\end{array}$} \\
\hline & Black Bengal & Boer & Jamunapari & \\
\hline Volume (ml) & $0.98^{b} \pm 0.14(40)$ & $1.73^{\mathrm{a}} \pm 0.16(40)$ & $1.49^{\mathrm{a}} \pm 0.19(40)$ & $*$ \\
\hline Sperm count per field & $553.94^{\mathrm{b}} \pm 51.01$ & $918.14^{a} \pm 58.33(38)$ & $971.60^{\mathrm{a}} \pm 54.30(39)$ & $* *$ \\
\hline Concentration $\left(10^{9}\right)$ & $0.089^{b} \pm 0.01(38)$ & $0.149^{\mathrm{a}} \pm 0.01$ & $0.158^{\mathrm{a}} \pm 0.01(38)$ & $* *$ \\
\hline TM (\%) & $55.47^{a} \pm 3.17(39)$ & $52.27^{\mathrm{a}} \pm 3.62(38)$ & $40.67^{b} \pm 3.37(38)$ & $* *$ \\
\hline FPM (\%) & $47.23^{\mathrm{a}} \pm 2.74(39)$ & $43.98^{a} \pm 3.13(38)$ & $30.97^{b} \pm 2.91(38)$ & $* *$ \\
\hline FM (\%) & $37.62^{\mathrm{a}} \pm 2.40$ (39) & $32.25^{\mathrm{a}} \pm 2.74(38)$ & $21.81^{b} \pm 2.55$ & $*$ \\
\hline SM (\%) & $9.45 \pm 0.89(39)$ & $11.67 \pm 1.02(38)$ & $9.06 \pm 0.95(38)$ & NS \\
\hline LM (\%) & $8.23 \pm 1.83(39)$ & $8.27 \pm 2.10(37)$ & $9.69 \pm 1.95(38)$ & NS \\
\hline Imotility (\%) & $44.53^{b} \pm 3.17(38)$ & $47.73^{b} \pm 3.62(37)$ & $59.21^{a} \pm 3.37(37)$ & $*$ \\
\hline CM (\%) & $0.16 \pm 0.04(38)$ & $0.05 \pm 0.04(37)$ & $0.08 \pm 0.05(37)$ & NS \\
\hline
\end{tabular}

TM=Total Motility, FPM=Forward Progressive Motility, FM=fast motility, FM=Fast motility, SM=Slow motility, LM=Local motility, CM=Circular Motility; Means with different superscripts within the same row differed significantly; $* *=$ Significant at $1 \%(p<0.01)$ level of probability, $*=$ Significant at $5 \%(p<0.05)$ level of probability, NS=Non-significant; Figures in the parentheses indicate the number of observation.

Table 3: Least square means along with standard error for velocity parameters of three genetic groups of bucks

\begin{tabular}{|c|c|c|c|c|}
\hline \multirow{2}{*}{ Parameter } & \multicolumn{3}{|c|}{ Genotype } & \multirow{2}{*}{$\begin{array}{c}\text { Level of } \\
\text { Signific } \\
\text { ance }\end{array}$} \\
\hline & Black Bengal & Boer & Jamunapari & \\
\hline \multicolumn{5}{|c|}{ Distance $(\mu \mathrm{m})$} \\
\hline $\mathrm{DCL}$ & $22.07 \pm 4.36(39)$ & $29.13 \pm 4.87(38)$ & $24.18 \pm 4.68(39)$ & NS \\
\hline DSL & $4.38^{\mathrm{b}} \pm 1.19(39)$ & $12.29^{\mathrm{a}} \pm 1.63(38)$ & $3.14^{\mathrm{b}} \pm 1.27(39)$ & $* *$ \\
\hline DAP & $7.26^{b} \pm 1.57(39)$ & $15.89^{\mathrm{a}} \pm 1.95$ & $8.42^{b} \pm 1.95$ & $* *$ \\
\hline \multicolumn{5}{|c|}{ Velocity $(\mu \mathrm{m} / \mathrm{s})$} \\
\hline VCL & $63.73^{b} \pm 11.51(38)$ & $127.08^{\mathrm{a}} \pm 13.88$ & $62.01^{b} \pm 12.77(38)$ & $* *$ \\
\hline VSL & $16.38^{\mathrm{b}} \pm 6.17(38)$ & $50.01^{a} \pm 7.68$ & $15.75^{b} \pm 7.35$ & $* *$ \\
\hline VAP & $24.26^{b} \pm 5.83(38)$ & $68.13^{\mathrm{a}} \pm 7.25(37)$ & $22.39^{b} \pm 9.42(38)$ & $* *$ \\
\hline $\mathrm{RD}$ & $1.30^{\mathrm{b}} \pm 0.30$ & $2.94^{\mathrm{a}} \pm 0.34$ & $1.17^{\mathbf{b}} \pm 0.32(38)$ & $*$ \\
\hline ROT & $0.09^{b} \pm 0.04$ & $0.26^{\mathrm{a}} \pm 0.05$ & $0.02^{b} \pm 0.05$ & $*$ \\
\hline $\mathrm{BCF}(\mathrm{Hz})$ & $7.69 \pm 1.77(38)$ & $9.38 \pm 2.03(37)$ & $5.69 \pm 1.89(38)$ & NS \\
\hline
\end{tabular}

$\mathrm{DCL}=$ Distance Curved Line, DSL=Distance Straight Line, DAP=Distance Average Path, VCL=Curvilinear Velocity, VSL=Straight line Velocity, $\mathrm{VAP}=$ Average Path Velocity, $\mathrm{RD}=$ Radius, $\mathrm{ROT}=$ Rotation and $\mathrm{BCF}=\mathrm{Beat}$ Cross-Frequency, LIN=Linearity, STR=Straightness, WOB=Wobble, $* *=$ Significant at $1 \%(p<0.01)$ level of probability, $*=$ Significant at $5 \%(\mathrm{p}<0.05)$ level of probability; NS=Non-significant; Figures in the parentheses indicate the number of observations. 
Similarly significantly $(p<0.05)$ highest radius and rotation value was observed in Boer bucks $(2.94 \pm 0.34$ and $0.26 \pm 0.05 \mu \mathrm{m} / \mathrm{s})$ than Black Bengal and Jamunapari bucks $(1.30 \pm 0.30$ and $0.09 \pm 0.04 ;$ and $1.17 \pm 0.32$ and $0.02 \pm 0.05$ $\mu \mathrm{m} / \mathrm{s})$, respectively. But there was non significant $(p>0.05)$ variation among the different genetic groups of bucks for beat cross-frequency. In sperm progression, there was no significant variation among the different genetic groups of bucks for linearity, straightness and wobble. Linearity (LIN \%) percent that reflects linearity of the curvilinear trajectory and is ratio of (VSL/VCL) was recorded to be 25.53 \pm 5.71 , $36.00 \pm 6.53$ and $28.20 \pm 1.07 \%$ for Black Bengal, Boer and Jamunapari bucks, respectively (Table 4). While straightness (STR\%) that represents the straightness of average path is ratio of VSL to VAP was found to be $53.59 \pm 6.78,71.64 \pm 8.43$ and $63.83 \pm 8.07$ for Black Bengal, Boer and Jamunapari bucks, respectively.

Relationship between scrotal circumferences and ejaculate volume

Figure 1 represents a regression equation ( $y=$ $0.096 x-1.071, y=0.094 x-0.887$ and $y=$ $0.108 x-1.378)$ and coefficient of determination $\left(\mathrm{R}^{2}=0.190, \mathrm{R}^{2}=0.025\right.$ and $\left.\mathrm{R}^{2}=0.022\right)$ between ejaculate volume and scrotal circumference of Black Bengal, Boer and Jamunapari bucks, respectively.

\section{Discussion}

Testicular circumference is an indirect measurement of the testicular mass. It is a major component in breeding soundness assessment, mainly because it is easy and reliable, and provides an indication of size and growth (Chacon et al., 1999). Keith et al. (2009) and Shamsuddin et al. (2000) showed values for scrotal circumference of Boer and Black Bengal bucks was 26.4 and 14.0 to $16.0 \mathrm{~cm}$ which is lower than the present result. According to Dhar et al. (2010) and Zinat et al. (2013) reported scrotal circumference of Black Bengal bucks was 21.5 and $20.00 \mathrm{~cm}$ which are almost similar to present findings. Raji et al. (2008) reported $23.17 \mathrm{~cm}$, while Adedeji and Gbadamosi (1999) reported $22.6 \mathrm{~cm}$ for Red Sokoto bucks at 2 years of age. The variability may be due to breed difference, contemporary group level, age, weight and height of bucks (Bourdon and Brinks, 1986). It is evident that scrotal circumference has a positive correlation with the amount of sperm production

Ejaculate volume, concentration and motility are considered an important parameter for the evaluation of fresh semen quality in bovines and other domestic species. Das et al. (2006), Suyadi (2012) and Kharche et al. (2013) reported semen volume which ranged from 0.16 to $0.51,0.97$ to 1.07 and $0.54 \mathrm{ml}$ in black Bengal, Boer and Jamunapari buck, respectively which is slightly lower than the values of the present study. Variation in semen volume reported by different researchers might be due to differences in genetics, reproductive health status of bucks, age of bucks, frequency of collection, pooled volume, nutrition, season and management (Soderquist et al., 1992). Variations can also be due to skill of semen collector and properly preparation of AV sets.

Findings on sperm concentration in this study are not in agreement with the findings of Karim (2008) who reported sperm concentration of between $2.75 \pm 0.28$ and $3.24 \pm 0.37$ billion $/ \mathrm{ml}$ in black Bengal buck; and Khan (1999) who reported the average sperm concentration of $3777.93 \pm 142.76$ million $/ \mathrm{ml}$, respectively. These are higher than the result of the present study. Leon et al. (1991) and Sharma et al. (1991) reported that sperm concentration might vary according to variation in age, breed, collection frequency, feeding regime and climatic condition.

Table 4: Least square means along with standard error for progression parameters of three genetic groups of bucks

\begin{tabular}{lcccc}
\hline \multirow{2}{*}{ Parameter } & \multicolumn{3}{c}{ Genotype } & $\begin{array}{c}\text { Level of } \\
\text { Significance }\end{array}$ \\
\cline { 2 - 5 } & Black Bengal & Boer & Jamunapari & NS \\
\hline LIN (VSL/VCL) & $25.53 \pm 5.71(38)$ & $36.00 \pm 6.53(37)$ & $28.20 \pm 1.07(38)$ & NS \\
STR (VSL/VAP) & $53.59 \pm 6.78(38)$ & $71.64 \pm 8.43(37)$ & $63.83 \pm 8.07(38)$ & NS \\
WOB (VAP /VSL) & $42.00 \pm 4.14(38)$ & $55.15 \pm 4.74(37)$ & $45.06 \pm 4.41(38)$ & \\
\hline
\end{tabular}

$\mathrm{LIN}=$ Linearity, STR=Straightness, $\mathrm{WOB}=$ Wobble, NS=Non-significant; Figures in the parentheses indicate the number of observation. 

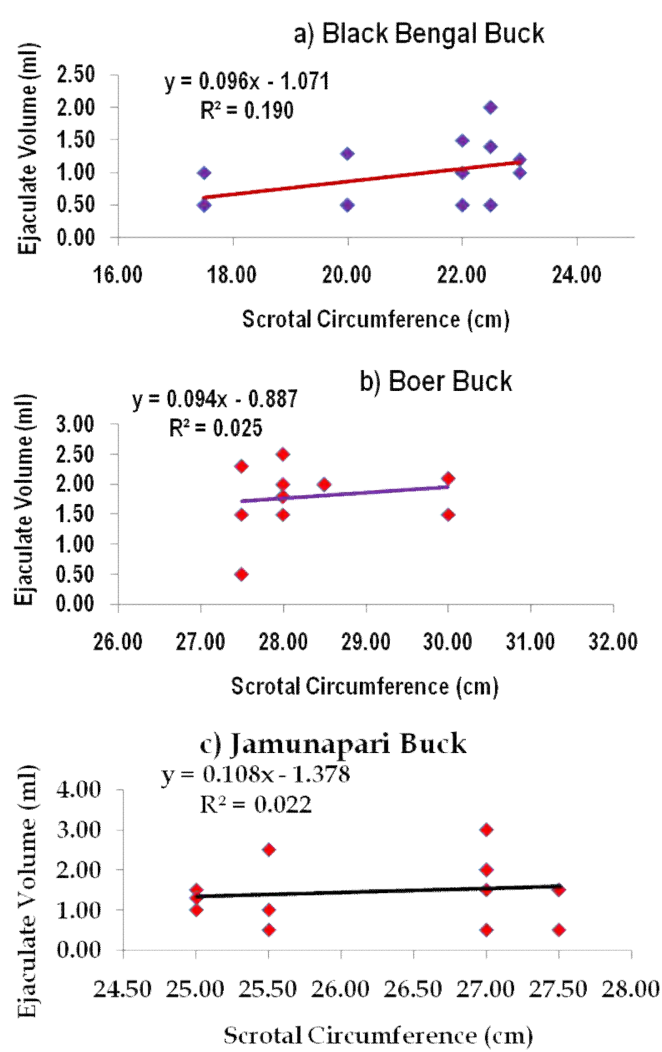

Figure 1: The regression equation and coefficient of determination $\left(R^{2}\right)$ for scrotal circumference in a) Black Bengal bucks, b) Boer buck and c) Jamunapari Buck.

According to Apu et al. (2012) and Afroz et al. (2008), the average sperm concentrations of buck semen were $2678.33 \pm 30.59$ to $2913.33 \pm 46.23$ and $2434.00 \pm 52.81$ to $2853.00 \pm 90.12$ million $/ \mathrm{ml}$, respectively. These are also higher than the present results. Das et al. (2006) and Mittal (1982) also reported higher values. Tekin and Daskin (2016) reported sperm motility $79.30 \%$ in Norduz goat semen after initial dilution which is higher than the present study. Anand and Yadav (2016) reported sperm motility in tris-glycerol diluted semen was 79.15, $13.40,56.10$ and $9.70 \%$ for total, rapid, slow and non-progressive motility in Sirohi goat. VCL, VAP and VSL are considered to be the most important characteristics to parameters utilized to evaluate the kinematic characters and have a positive correlation the fertilizing ability of spermatozoa (Jobling et al., 2002). Higher values for these parameters exhibited by spermatozoa are indicative of better conception rate in farm animals. Kozdrowski et al. (2007) showed mean VAP, VSL and VCL in frozen goat semen was 78.33, 68.46 and $129.20 \mu \mathrm{m} / \mathrm{s}$, respectively. Anand and Yadav (2016) reported sperm velocity in tris-glycerol diluted semen was 96.75, 41.00, $34.50 \mu \mathrm{m} / \mathrm{s}$ for VCL, VAP and VSL, $19.00 \mathrm{hz}$ for $B C F$, respectively in Sirohi goat which is slightly lower than the present findings. While Dorado et al. (2009) and Anand et al. (2016) recorded higher values in Florida and Barbari bucks. Linearity is correlated to sperm in vitro migration efficiency, where spermatozoa presenting values of LIN > 50\% showed better migration (Cox et al., 2006). Both linearity and ALH seem to be indicators of sperm hyperactivation (Pena et al., 2000). Higher values of linearity percent is indicative of better capacity of spermatozoa to migrate through female reproductive tract and is indicative of timely transport of spermatozoa to the site of fertilization (Cox et al., 2006). The spermatozoa with higher values of LIN and STR of spermatozoa in semen sample may be thought to have better capacity to overcome barriers in reproductive tract and hence, better conception rate. Values recorded during study were lower than that reported in Florida bucks and Barbari (Dorado et al., 2007 and Anand et al. 2016).

The coefficient of determination $\mathrm{R}^{2}$ indicated that scrotal circumference accounts for $19 \%$ in Black Bengal bucks, $2 \%$ in Boer bucks and $2 \%$ in Jamunapari bucks in predicting ejaculate volume. The $R^{2}$ values obtained from the regression analysis of this study shows that scrotal circumference was reliable in predicting ejaculate volume. The variation could be attributed by the breed, plane of nutrition, management practices and variation in climatic conditions.

\section{Conclusion}

CASA system used in this study was first time in Bangladesh to evaluate the buck semen motility and velocity parameters. It was minimized time and labor. Out of three goat genotypes, Boer semen characteristics comparatively found better than others. Further, competitive studies with large sample may be performed to evaluate the breed specific differences in available goat breeds for better understand of spermatozoa kinematics and establishing correlation with different factors influencing motility and fertility rate which will be helpful in determining of conception rate in goat population throughout country 


\section{Acknowledgement}

The authors really want to thank the director of American Dairy Limited for providing funds and pursue the study.

\section{Conflict of interest}

The author has no conflict of interest to declare.

\section{References}

Adedeji OS and AJ Gbadamosi (1999). Relationship of scrotal circumference to age, bodyweight and the right and left scrotal length in the Red Sokoto goats. In: Proceedings of 26th annual Conference of Nigerian Society for Animal Production, Ilorin, Nigeria, pp. 10-13.

Afroz S, M Islam, MAMY Khandoker and Q Akter (2008). Cryopreservation of Black Bengal buck semen: Effects of diluents and freezing on sperm motility and morphology. Animal Science Journal 79(5):550-553.

Anand M and S Yadav (2016). Assessment of motion and kinematic characteristics of frozen thawed Sirohi goat semen using computer-assisted semen analysis. Veterinary World 9(2):203-206.

Anand M, S Yadav, J Kumar and AK Madan (2016). Assessment of motion characteristics and path velocities exhibited by Barbari buck spermatozoa. Veterinary Practitioner 17(2):263264.

Apu AS, MAMY Khandoker, SS Husain, M Fakruzzaman and DR Notter (2012). A comparative study of fresh and frozen-thawed semen quality in relation to fertility of Black Bengal goats. Iranian Journal of Applied Animal Science 2(2): 157-161.

Bhatia S and R Arora (2005). Biodiversity and conservation of Indian sheep genetic resourcesAn Overview. Asian-Australasian Journal of Animal Sciences 18(10):1387-1402.

Bourdon RM and JS Brinks (1986). Scrotal circumference in yearling Hereford bulls: Adjustment factors, heritability and genetic, environmental and phenotypic relationships with growth traits. Journal of Animal Science 62(4): 58-967.

Chacon J, E Perez, E Muller, L Söderquist and H Rodriguez-Martinez (1999). Breeding soundness evaluation of extensively managed bulls in Costa Rica. Theriogenology 52(2):221-231.

Cox JF, V Alfaro, V Montenegro and H RodriguezMartinez (2006). Computer-assisted analysis of sperm motion in goats and its relationship with sperm migration in cervical mucus. Theriogenology 66(4):860-867.

Das SK, SS Husain, MR Amin, T Munim, MA Hoque and MAMY Khandoker (2006). Growth performance of progeny using selected Black Bengal bucks. Bangladesh Journal of Animal Science 35(10): 27-35.
Dhar AC, AK Talukder, MB Rahman, AA Mamun and M Shamsuddin (2010). Semen quality of Black Bengal bucks used at commercial artificial insemination. Journal of Embryo Transfer 25: 237-245.

Dorado J, M Hidalgo, A Muñoz and I Rodríguez (2009). Assessment of goat semen freezability according to the spermatozoa characteristics from fresh and frozen samples. Animal Reproduction Science 112(1-2):150-157.

Dorado J, I Rodríguez and M Hidalgo (2007). Cryopreservation of goat spermatozoa: comparison of two freezing extenders based on post-thaw sperm quality and fertility rates after artificial insemination. Theriogenology 68(2): 168-177.

Jabbar MA, SS Husain, SMF Islam, MR Amin, MAMY Khandaker, AKFH Bhuiyan, SZ Ali and O Faruque (2010). Stakeholder prespectives on breeding strategy and choise of breeds for livestock development in Bangladesh. Bangladesh Journal of Animal Science 39(1/2): 20-43.

Jobling S, S Coey, JG Whitmore, DE Kime, KJ Van Look, BG McAllister, N Beresford, AC Henshaw, G Brighty, CR Tyler and JP Sumpter (2002). Wild intersex roach (Rutilus rutilus) have reduced fertility. Biology of Reproduction 67(2): 515-524.

Karim MF (2008). Comparison of different diluters for frozen semen production in Black Bengal bucks. MS thesis. Department of Animal Breeding and Genetics, Faculty of Animal Husbandry, Bangladesh Agricultural University, Mymensingh, Bangladesh, pp. 49-56.

Keith CO, S Solaiman and O Tiller (2009). Accuracy of predicting body weights from body conformation and testicular morphormetryin pubertal Boer goats. Research Journal of Animal Science 3(2):26-31.

Khan RA (1999). A quantitative study on semen characteristics of Black Bengal buck. MS thesis, Department of Animal Breeding and Genetics, Bangladesh Agricultural University, Mymensingh, Bangladesh, pp. 78-92.

Kharche SD, SK Jindal, R Priyadharsini, K Satish, AK Goel, N Ramachandran and PK Rout (2013). Fertility following frozen semen artificial insemination in Jamunapari goats. Indian Journal of Animal Science 83(10):1071-1073.

Kifaro GC, LO Eik, LA Mtenga, DE Mushi, J Safari, AA Kassuku, EN Kimbita, AD MaedaMachang'u, NL Kanuya, VRM Muhikambele, E Ndemanisho and MJ Ulvund (2007). The potential use of artificial insemination in sustainable breeding of dairy goats in developing countries: A case study of Norwegian dairy goats in Tanzania. Tanzania Journal of Agricultural Sciences 8:19 - 24.

Kozdrowski R, A Dubiel, W Bielas and M Dzięcioł (2007). Two Protocols of Cryopreservation of Goat Semen with the Use of Computer-Assisted Semen Analysis System. Acta Veterinary Brno 76(4):601-604. 
Islam et al. (2019) Bang. J. Anim. Sci. 48 (2):67-74

Leboeuf B, B Restall and S Salamon (2000). Production and storage of goat semen for artificial insemination. Animal Reproduction Science 62(1-3):113-141.

Leon H, AA Porras and CS Galina (1991). Effect of the collection method on semen characteristics of Zebu and European type cattle in the tropics. Theriogenology 36(3):349-355.

Mittal JP (1982). Seasonal variation in semen quality of Barbari bucks. Indian Veterinary Journal 59:957-959.

MoFL (2013). Department of Livestock Services, Ministry of Fisheries and Livestock (MoFL), Government of the People's Republic of Bangladesh, Dhaka.

Pena A and C Linde-Forsberg (2000). Effects of Equex, one- or two-step dilution, and two freezing and thawing rates on post-thaw survival of dog spermatozoa. Theriogenology 54(6): 859-875.

Raji AO, Igwebuike and J Aliyu (2008). Testicular biometry and its relationship with body weight of indigenous goats in a semi arid region of Nigeria. Journal of Agricultural and Biological Science 3(4):6-9.

SAS (2009). Statistical Analysis System, Computer Software, Version 9.1.3: Statistics SAS Institute Inc. Cary, NC 27513, NC27513, USA.

Shamsuddin M, Y Amiri and MMU Bhuiyan (2000). Characteristics of buck semen with regard to ejaculate numbers, collection intervals, dilution and preservation periods. Reproduction of Domestic Animal 35(2):53-57.
Sharma ML, G Mohan and KL Sahni (1991). Characteristics and cryopreservation of semen of Holstein Friesian bulls under tropics. Indian Journal of Animal Science 61:977-979.

Soderquist L, L Janson, M Haard and S Einarsson (1992). Factors affecting the variation in sperm morphological abnormalities in Swedish dairy A.I. bulls. Proceedings of 12th International Congress on Animal Reproduction. August 2327, The Hague, Netherlands.

Suyadi S (2012). Sexual behaviour and semen characteristics of young male Boer goats in tropical condition: A case in Indonesia. International Journal of Biological. Biomolecular, Agricultural, Food and Biotechnological Engineering 6(6):388-391.

Tekin K and A Daşkin (2016). Effect of different extenders on motility and some sperm kinematics parameters in Norduz goat semen. Turkish Journal of Veterinary Animal Science 40:490-495.

Verma OP, A Kumar and S Chand (2012). Assisted reproductive techniques in farm animal - from artificial insemination to nano biotechnology. Veterinary World 5(5):301- 310.

Zinat M, MAMY Khandoker and MN Haque (2013). Effect of non genetic factors on productive traits of Black Bengal goats. Journal of Bangladesh Agricultural University 11(1):79-86. 